\title{
MARKET EXPERT \\ SURVEILLANCE SYSTEM
}

\author{
by \\ Henry C. Lucas, Jr.
}




\title{
MARKET EXPERT SURVEILLANCE SYSTEM
}

\author{
by \\ Henry C. Lucas, Jr. \\ Information Systems Department \\ Leonard N. Stern School of Business \\ New York University \\ 90 Trinity Place \\ New York, New York 10006
}

February 1990

Center for Research on Information Systems Information Systems Department Leonard N. Stern School of Business

New York University

\section{Working Paper Series}

STERN IS-90-3 


\title{
MESS: MARKET EXPERT SURVEILLANCE SYSTEM
}

\begin{abstract}
MESS is an expert system to support a decision at the American Stock Exchange to open an investigation of insider trading. The system was developed with three experts and extensive prototyping. MESS illustrates multiple roles for an expert system; it contributes to decision making by seeing that all relevant factors are considered, stimulating discussion of important criteria, and providing an audit trail for regulatory review, The system also serves a training role for a position with historically high turnover. ${ }^{1}$
\end{abstract}

\section{INTRODUCTION}

The American Stock Exchange is one of the major markets for the exchange of stock and for raising capital in the United States. The Exchange is responsible for monitoring trading to be sure that securities rules are not violated. At the American Stock Exchange (AMEX), the responsibility for this monitoring is shared between two departments: Stock Watch and Equities Surveillance. This paper reports on the development of an Expert System to assist the Equities Surveillance Department investigate possible violations of insider trading rules.

\section{Contribution of the Research}

This project has provided insights into the design and use of expert systems in the financial industry. In particular, the systems development effort has:

1. Suggested multiple roles for an expert system including:

a. A control system to be sure that all factors are considered in making a decision,

b. A vehicle for stimulating discussion among decision makers and focusing attention on all criteria important in a decision problem, c. A device for training new decision makers,

1 The author wishes to thank Mrs. Margaret Lucero of the American Stock Exchange for her collaboration on the development of MESS; Professors Rob Kauffman and Vasant Dhar and Mr. Don Berndt provided a number of helpful comments on earlier versions of the paper 
d. An audit trail demonstrating consistency in making a large number of similar decisions.

2. Emphasized the importance of the user interface in building production expert systems;

3. Illustrated the development phases suggested by Waterman (1986) and provided insights on some of the pitfalls that hinder the development of expert systems;

4. Demonstrated how a project to build a low-cost expert system using prototyping expanded to become a more generalized decision support system.

There have been other expert systems developed in finance, for example, see Reitman (1984), Dhar and Croker (1988). However, previous systems have generally dealt with financial analysis (Mui and McCarthy 1987), planning (Stansfield and Greenfeld, 1987) or investments (Heuer, Koch and Cryer, 1988) . rather than surveillance for improper behavior.

\title{
Developing an Expert System
}

Waterman (1986) has suggested a number of steps in the development process for an expert system including:
Identification
Conceptualization
Formalization
Implementation
Testing

He also suggests that the system, itself, passes through a number of stages including:

\author{
Demonstration prototype \\ Research prototype \\ Field prototype \\ Production model \\ Commercial system
}


Waterman's framework will provide the basis for a discussion of the implementation of MESS later in the paper.

\section{The Domain}

\section{Motivation for an Expert System}

Why develop an expert system for surveillance? The problem of detecting possible insider trading, described in more detail below, involves reasoning based on both numerical calculations and logic. The most significant considerations in making decisions are logical and much of the decision process can be described in rules. The Equities Surveillance Department at the AMEX has a history of high employee turnover; the typical analyst spends a year in the department. An Expert System (ES) should help in providing continuity and in training new analysts. In fact, the original development effort was justified purely on training considerations.

\section{Insider Trading}

The U.S. Government and the securities industry generally regard insider trading as unsportsmanlike and illegal. A strict definition of insider trading is difficult; in general, anyone who takes advantage of important information not generally available to the public to make a profit trading securities may have violated insider trading laws.

Insider trading is likely to occur around some type of company announcement. For example, suppose that a firm is about to announce record earnings for the past quarter. An individual who had advance news of the earnings might buy stock in the firm before the announcement in the expectation that such good news would cause the stock price to rise. If the buyer is correct and the stock price rises after the news announcement, he or she can sell the stock at a profit.

The insider information in this case might come from a company employee, an accounting firm employee, or some other source. Since the individual had 
information not generally available to the public in advance of the news announcement, he or she could be charged with insider trading. In this instance, because the news announcement was favorable, the investor would have made a gain from insider trading.

If a news announcement is unfavorable, an investor with insider information might sell shares in the company to avoid a loss. He or she might also sell "short;" that is, sell shares not owned. The investor expects the stock price to fall so that he or she can cover the short sale in the future with stock that costs less than the sale price.

It is fairly easy to suspect insider trading; it is far more difficult to develop a strong case and prove that it actually occurred. In the example above, if the earnings for the company in question had been steadily rising over the past few quarters, an investor might expect them to continue to rise and therefore purchase stock in anticipation of a scheduled quarterly earnings announcement. Past information on earnings is publicly available, so there might be no case for insider trading. In looking for insider trading, the investigator has to weigh the factors which might lead to a suspicion of a violation against mitigating evidence which suggests that nothing illegal took place.

\section{Market Surveillance}

Figure 1 describes the market surveillance process in equities (shares of stock in a firm listed on the Exchange) at the American Stock Exchange. It is easiest to conceptualize the surveillance process as a large funnel. Potential cases of insider trading are dropped into the top of the funnel; at various places in the review process, cases are dropped until only a few emerge at the bottom of the funnel. Out of thousands that are poured in at the top, only a handful emerge to be sent to the Securities and Exchange Commission (SEC) for possible legal action. 


\section{Equities Surveillance}

Equities Surveillance receives referrals from a number of entities including the Stock Watch Department, specialists, brokers, exchange officials and others. The most frequent source is Stock Watch; this department applies a statistical model to daily trading to detect unusual price or volume movements in a security. Given that a stock is behaving in an unusual manner, the Stock Watch staff looks for possible explanations. When they observe unusual activity before an announcement, they refer the case to Equities Surveillance.

Within Equities Surveillance an analyst collects data and makes a presentation to a supervisor. The supervisor and analyst make a decision on whether to pursue the case or drop it. If the decision is to open an investigation, the analyst collects a great deal of information which is then reviewed a second time with the supervisor.

There are considerable differences between the two decisions described above. In the initial screening, the many of the cases will be filed without action.. The initial investigation involves only data that are already available at the Exchange, for example, information on stock volume and price movements, news announcements, past earnings, the activity of brokerage firms around the period in question, and the potential profits that an insider could make.

If a decision is made at the initial screening to open an investigation, then the analyst will generally request external data. The securities industry is largely selfregulating; firms that are members of the Exchange are required to provide data for investigations. An analyst might ask for a list of all trades and the identity of the customers for a stock during a given period. Equities Surveillance can even require a broker to come to the Exchange and answer questions about trades.

Because there are a large number of referrals and since a full investigation consumes considerable resources, the initial screening is important. The objective 
of this screening is to eliminate cases in which insider trading is unlikely or cases in which the chance of prosecution is very small. For example, if the likely gain from insider trading is below a certain threshold amount, the SEC will probably not prosecute.

\section{MESS}

The Market Expert Surveillance System (MESS) was developed to provide assistance during the initial screening of insider trading referrals. The system also has some rules related to market manipulation and unusual activity, but most of the development effort focused on insider trading. A schematic of the system is shown in Figure 2.

\section{Obtaining Mainframe Data}

Original plans were for a simple expert system; however the effort expanded as explained in the next section to include a number of other components. The first step in running the expert is to determine the date of the announcement which triggered the investigation. This date along with the stock's ticker system is entered into an AMEX IBM VM inquiry system. An APL procedure retrieves the stock's price and volume on the day of the announcement, two days following the announcement and fifty days preceding it. These data are downloaded using an IRMA board to produce an ASCII file on a PC.

\section{A Lotus Program}

Next, the user runs a batch file which controls the expert. The first step is to run a Lotus program that inputs the raw data from the VM system into a spreadsheet; the spreadsheet has custom menus and macros to assist the Equities Surveillance analyst. He or she must first identify the period of interest, that is, the time during which the suspected violation occurred. The spreadsheet, given the period of interest, calculates a number of statistics that will be used later by the 
expert system. For example, the expert is interested in the volume of shares bought during the period of interest and in the two days following the news announcement. The system also needs to know the high and low prices of the stock during and after the period of interest.

The user can graph price and volume as an aid to choosing the date beginning the period of interest. In the case of an announcement that occurred during trading hours, the analyst may move volume after the announcement to the two days following the news to get a more accurate picture of trading. When the analyst has made a final decision on the period of interest after possibly trying several, he or she exits the Lotus program. The spreadsheet passes data to the next program in the system.

\section{The ES Interface}

The expert system, itself, was developed using EXSYS, a rule-based expert systems shell for a personal computer. (For a further discussion of rule-based systems, see Hayes-Roth, 1985). Exsys acquires data by asking the user questions and each question appears on a separate screen. For this surveillance application, there are a large number of events which could happen and generate a news announcement. However, it is unlikely that more than one or two would happen for any investigation. There is also information which the expert requires each time it is run, information like the number of shares bought and sold by the three most active brokerage firms and the specialist firm in the stock.

Early in the development of MESS, it became evident that answering a series of questions sequentially, one screen at a time, was an irritation for users. A package called Screen Sculptor, written in Quick Basic, interfaces with EXSYS. This package makes it possible to design custom forms to collect input data and pass the information easily to EXSYS. 
A systems analyst at the AMEXX used Screen Sculptor to develop a series of three input screens which capture about $80 \%$ of the data needed by the Expert System. The most frequent answers are already marked so the user only has to change them if this case does not conform to the answers, for example, most often the investigation comes from a referral by Stock Watch. In only a few seconds the user can place an $\mathrm{X}$ by the news announcement(s) that pertain in this situation. This process is considerably smoother than answering a number of questions "no" and a few "yes" as would be required without the interface program.

\section{The Expert System}

The final part of the system is the expert, itself. Figure 3 presents two rules from the expert to illustrate the system. Rule 138 is mathematical; if the investigation is for insider trading and the analysis is being done on the sell side, (for loss avoidance $([E X P E C T E D M O V E M E N T]<0)$, and the three largest sellers have an average percentage of total volume greater than $\mathrm{X}$, then investigate with a confidence of $\mathrm{Y}$. In MESS, the $\mathrm{X}$ and $\mathrm{Y}$ values are numerical; the actual numbers have been omitted in Figure 3 in order not to provide hints to inside traders.

Rule 130 applies to a particular type of news announcement, a takeover or merger. If the AMEX company is being acquired, and the price of the stock has moved by $\mathrm{X}$ percent, then investigate with a confidence of $\mathrm{Y}$. In a merger or takeover, the stock price of the acquired company usually rises. The evidence for opening an investigation in case of a merger or acquisition depends on the extent of price movement, among other factors.

One of the key features of the expert is its attempt to satisfy two seemingly conflicting goals: open an investigation and do not open an investigation. Earlier the paper described the fact that there is evidence in favor of opening an investigation, but that the evidence has to be balanced against mitigating circumstances. Rather than provide a single recommendation to the user, MESS 
provides two outputs, each with a weight. Thus, MESS might analyze a case and provide the following recommendations:

Open an investigation $\quad \mathrm{p}=65$

Do not open $\quad \mathrm{p}=45$

In this example, the system finds the evidence in favor of an investigation to be greater than the data indicating not to open. A larger weight means that more significant rules or more rules in general fired than a smaller weight. While the absolute magnitude of a weight does not form an interval scale, weights of 10 or 20 mean that there is not a lot of evidence while weights of 75 and above generally indicate that a number of rules, some with high weights, fired.

In addition to providing output recommendations, the system displays a number of significant pieces of data so the analyst can view them with the recommendation. For example, the system computes and displays the maximum potential gain or loss avoidance from insider trading, that is, given the number of shares that were traded, the stock price, and the time period of the investigation, what is the maximum gain that one could have made trading on insider information? When the analyst is finished, the system prints a report containing salient data and a trace of all rules that fired for audit trail purposes.

To arrive at its recommendations, MESS backward chains through a number of rules. As of this writing, the system has approximately 160 rules. First it analyzes the news to determine whether insider trading was most likely on the buy side (gain) or sell side (loss avoidance). After making a decision, the system asks the user to confirm as sometimes news can be misleading; the analyst has the option of changing the system's decision at this point.

The decision on the buy or sell side for the analysis determines what statistical data are used in the analysis and, of course, how the maximum profit potential is calculated. Next the system works on the two goals of "investigate" or " 
do not investigate," applying a number of rules provided by the experts. The system may request additional information in testing certain rules, information that could not be anticipated in advance and entered in the previous program.

Each rule has a p value associated with it indicating how much weight this rule should be given in opening or not opening an investigation. A good example of weighting comes in the area of profit potential. The highest weight for not opening on profit potential is if there is no potential profit. The weights for the "do not open" recommendation decrease as profit potential approaches a particular breakpoint; at the breakpoint, a weight for investigation begins and builds as profit potential increases. The $\mathrm{p}$ values are combined as additional rules fire using a multiplicative formula:

$$
\mathrm{P}_{\text {combined }}=1-\left(\left(1-\mathrm{P}_{\text {old }}\right) *\left(1-\mathrm{P}_{\text {new }}\right)\right)
$$

thus, additional information has less and less weight.

\section{SYSTEMS DEVELOPMENT}

Earlier, Waterman's framework for expert systems development was presented; this section applies that framework to the development of MESS. Waterman's first phase is identification; the problem of surveillance was identified as an important topic by officials at the AMEX because at the time the project was under discussion, there were a number of highly publicized insider trading cases being investigated.

To provide a broad conceptualization of the problem, the manager of the Equities Surveillance Department, a systems analyst from the AMEX and the author met to discuss the tasks of the department. The analyst and author were committed to developing a prototype so that the department manager could see immediate progress and maintain his interest in the project. Rapid prototyping 
moved the project quickly from the conceptualization phase to formalization, expressing the key concepts of the problem in a formal structure.

Within two weeks of the first meeting, the manager could look at a rough prototype with 15 rules developed in the expert systems shell. The system performed badly, but did show the manager the potential for expert systems. Within a few meetings, he added the two senior staff members in the department to form a team of experts. Because model development began so soon, to some extent both conceptualization and formalization proceeded together.

Much early development involved running completed cases through the prototype. The phases of implementation and testing also occurred in parallel. The variety of cases made it possible to quickly expand the system to include more rules. The presence of three experts meant that knowledge engineering involved a considerable amount of conflict resolution. The manager of the department tended to favor opening cases while the senior supervisors, possibly giving more consideration to workload and the effort involved in an investigation, tended to be biased against opening cases unless the evidence for insider trading was very strong.

Fairly soon in the design process, the need for a better user interface became apparent leading the systems analyst to acquire Screen Sculptor and begin building the questionnaire-type screens described earlier. After several months of development using past cases, the experts brought several newly referred cases which had yet to be analyzed. The designers noticed that the experts were doing a number of approximate calculations to obtain figures that had been readily available in past case folders.

The experts indicated that an analyst at his or her desk would first perform these calculations using a calculator and note the results before analyzing the case. Since the analyst was keying the numbers into the calculator, the experts agreed that they would be willing to key the data into a Lotus spreadsheet to do the calculations 
and pass the data to the expert system. This approach would reduce the number of input items requested by the system and would mean that key statistics could be computed automatically. Work began on a spreadsheet with custom menus and macros, a task that was not envisioned when the systems development project began.

The belief that the analyst would not mind entering data into a spreadsheet since the numbers were already being entered into a calculator proved incorrect. There were many complaints about having to type data into the system. The AMEX systems analyst working on the project devoted a great deal of effort to finding the needed data on an Exchange system and figuring out how to retrieve and format it as simply as possible. Thus, the final component of the system became the inquiry for price and volume data from the IBM mainframe. It is interesting to note that since the data could now be retrieved automatically and loaded into the spreadsheet, the experts decided to look at 53 days worth of data rather than the previous 33 .

\section{EVALUATION}

Evaluating the expert system was more difficult than originally foreseen due to a heavy workload in Equities Surveillance. After a number of months of effort, it was possible to get the department manager and two senior employees to independently review a series of referrals from Stock Watch and to compare their recommendations with those generated by an analyst using MESS.

Table 1 contains a brief summary of each case discussion and the results of the voting. Table 2 is a summary of the actual votes and recommendations from MESS. In cases $1,3,4,5,7$, and 8 MESS and the experts agreed. In case 6 only two experts performed the analysis and they were split. In case 2, MESS had a weight of 78 to open and 73 not to open while all three experts said no. Many of the MESS recommendations were fairly close, for example, in case 5 the weights are 63 and 58 . 
(Case 1 is 44 to 43 , but the analyst using MESS entered the wrong period of interest.)

Observations at the evaluation meeting suggest that the experts tended to focus on a few key facts. In Case 3, all the experts agreed not to open, but the major reason for each was different. The experts appeared to change the weights given to various factors dynamically; the weight is not independent of the magnitude of the factor. For example, in case $1 \mathrm{~F}$ put a much higher weight on limited profitability than the weights he gave to MESS for its rules on profitability.

MESS consistently applied its rules considering all information. The experts at times did not bother with certain data because other more significant items had already contributed to their decision. From the two tables it is also evident that the three experts do not always agree. MESS tended to highlight both sides of the case and called the analyst's attention to items that might be overlooked. It reduced the tendency to focus on a few indicators without considering all relevant factors.

\section{FURTHER IMPLEMENTATION}

Based on the evaluation meeting, the manager of Equities Surveillance decided to require analysts to use MESS for all new insider trading cases in which a decision was made not to open an investigation. A tool like MESS can help the analyst and others involved in the decision-making process be sure that an important reason for opening was not overlooked in the analysis.

Because the analysts still found the mainframe retrieval and downloading time-consuming, it was further decided that the AMEX systems analyst would train two clerical employees to download data to the PC. Then the analyst would only have to start the batch file on the PC to run the expert system.

The output of the system will help the analyst decide whether or not to recommend opening an investigation. The analyst often reviews decisions with the 
senior staff in Equities Surveillance. To some extent, the ES supports group decision making by focusing attention on agreed upon criteria for evaluating a case. While not providing the direct support of an AI tool like the Information Lens (Malone, et. al, 1987), an expert system can support a group faced with a repetitive decision involving criteria that should be consistently applied across all cases.

Even if the analyst differs with MESS, the system shows the reasons for its recommendations and the analyst can indicate exactly the reasons for disagreement. In particular, it is important for Equities Surveillance to defend its decisions not to open a case when the SEC audits the surveillance files. The printed output from MESS in cases where the Exchange staff and system agree should be adequate support for a "do not open" decision. If the analyst disagrees, he or she can note the reasons why he or she overrode the system's recommendations.

The manager of the department feels that the system will aid in training and assuring that there is some consistency in evaluating referrals. The system should also help see that a consistent set of facts is evaluated in each case. Finally, MESS will provide documentation of the reasons for a decision.

\section{Pitfalls}

Waterman suggests a number of pitfalls that an expert systems development effort can encounter; MESS was affected by several of them during its implementation. First, at times it was difficult to represent the problem domain using the expert systems tool. This problem became more significant as the scope of the system expanded beyond the rule-based expert to include data retrieval from the VM system and the Lotus front-end. In retrospect, it would have been difficult to avoid these problems given the decision to develop a prototype. A design that stressed completing specifications before any programming would probably have identified the full scope of the system, but this approach might have resulted in the 
expert losing interest in the project due to the time required before a working system could be demonstrated.

A second pitfall was the need to include multiple experts; while most developers warn against several experts, the presence of more than one expert helped the system develop balance. While time was spent resolving conflicts, the three experts provided a broader perspective on the problem; each tended to counter the biases of the others.

The third pitfall MESS encountered was some resistance on the part of analysts; each analyst does not have a PC and must go to a room containing the machine running MESS. To make it easier for the analysts, the department manager allowed his secretary to be trained to do the downloading from the VM system.

The system is now between Waterman's stages of research prototype and field prototype; it can be used to document decisions not to open an investigation. It also provides consistency and forces the analyst to look at all of the evidence in each case. If the Exchange is willing to invest in continued development, this prototype suggests developing a broader, production system that includes the stockwatch function.

\section{DISCUSSION}

The project to develop the Market Expert Surveillance System at the American Stock Exchange has illustrated that there can be multiple roles for an ES. The system can serve as a control to be sure that all relevant factors are considered in a decision. In fulfilling this role, the system also provides consistency across a number of different decision makers who are working on the same type of problem. As an advisory system, an ES may become the primary vehicle for stimulating discussion among different decision makers. For example, an analyst and the 
supervisor can use MESS as the basis for reviewing the analyst's recommendations on referrals. An expert system is an excellent way to train new employees in making a decision. The output of an ES can also be used as an audit trail where there is strict accountability for decisions.

Analyzing the development process using Waterman's phases suggests that, at least when prototyping is employed, there will be considerable overlap among the phases of development. In designing MESS, the conceptualization and formalization stages overlapped as did implementation and testing. This case suggests a modification to Waterman's framework to include cycles among the different phases. The development effort also encountered some of Waterman's pitfalls; the project suggests that it will be difficult to avoid some of these pitfalls, particularly when one is forced to deal with more than one expert.

The development effort for MESS indicated the extreme importance of the user interface in a production expert system; probably half of the development effort went into interface design and implementation. This project showed that it is possible to develop an expert system relatively inexpensively (less than $\$ 50,000$ ) on a microcomputer using available packages. While the system could be streamlined by a complete reprogramming, in this case the available resources have dictated that the prototype become the final system.

The potential for small, expert systems built around existing packages is great. In the future as managerial workstations become more prevalent, one can expect to see more expert systems developed to support decisions. These systems help the user apply consistent criteria and stimulate thinking on whether he or she agrees with the expert system. As MESS illustrates, these systems can be built economically using a combination of packages and access to mainframe databases. 


\section{REFERENCES}

Dhar, V. and A. Croker, "Knowledge-Based Decision Support in Business: Issues and a Solution." IEEE Expert, Spring 1988, pp. 53-62.

Hayes-Roth, F., "Rule-Based Systems," Communications of the ACM, Vol. 28, No. 9 (September 1985), pp. 921-932.

Heuer, S., U. Koch, and C. Cryer, "INVEST: An Expert System for Financial Investments," IEEE Expert, Summer 1988, pp. $60-68$.

Malone, T. K Grant, F. Turbak, S. Brobst, and M. Cohen, "Intelligent Information-Sharing Systems", Communications of the ACM, Vol. 30, No. 2, (May 1987), pp. 390-402.

Mui, C. and W. McCarthy, "FSA: Applying AI Techniques to the Familiarization Phase of Financial Decision Making, IEEE Expert, Fall 1987, pp. 33-41.

Reitman, W. (ed.), Artificial Intelligence Applications for for Business, Norwood, N.J., Ablex, 1984.

Stansfield, J. and N. Greenfeld, PlanPower: A Comprehensive Financial Planner, IEEE Expert, Fall 1987, pp. 51-60.

Waterman, D. A Guide to Expert Systems, Reading, Ma:, Addison-Wesley, 1986. 
Case 1
A No Increased revenues explain movement.
F No Limited profitability; announcement explained movement.
$R$ No Positive earnings, revenue announcement precedes earnings, low profitability.
MESS No (44) Yes (43) Low profitability, but high concentration (Analyst chose wrong period of interest)

Case 2

A No Price up on negative news; earnings anticipated.

$F$ No Light volume and low potential gain.

$R$ No Low profit potential; price fell after news.

MESS Yes (78) No (73) Very large price movement, but low profit potential, less than $\$ 3500$.

Case 3

A No Price fell prior to news; specialist most active and earnings favorable.

F No Favorable earnings followed by price increase.

$R$ No Specialist most active and earnings up consistently.

MESS No (78) Yes (5) Low profit potential; long term earnings up; favorable news outside period of interest; little volume change

Case 4

A Yes Price up prior to news

F No? Profitability low; unusual activity before news.

$\mathrm{R}$ Yes Price rise

MESS Yes (76) No (69) Earnings erratic or down (Analyst incorrectly input an earlier earnings report or system would have much lower "no" weight).

Case 5

A No Minimal loss avoidance; stock did not react to news

F ? Bad news and price increases, then favorable news.

$\mathrm{R}$ No Minimal loss avoidance; price up prior to negative news.

MESS No (63) Yes (58) Low gain, but high concentration; conflicting public announcements. 
Case 6

A Yes stock did not react, but one firm purchased over 100,000 shares.

F Did not evaluate

$\mathrm{R}$ No Could anticipate earnings; largest buyer also largest seller.

MESS Yes (79) No (72) Large potential gain; high buying concentration, but movement after news is down; earnings up and long term earnings trend is up.

Case 7

A No stock did not react; loss avoidance high as $F$ No Not enough movement.

$\mathrm{R}$ No Selling scattered; large firms active in stock.

MESS No (67) Yes (50) Large potential gain, but movement flat and small price changes.

Case 8

A No Price decline could be explained

$\mathrm{F}$ ? No going to yes. Price change not unusual; large buyer also sold, but very high potential gain.

$R \quad$ Did not evaluate

MESS No (59) Yes (49) Very large loss avoidance possible, other factors suggest no.

Table 1

Summary of Evaluation Cases 


\begin{tabular}{llllllllll} 
Cases & 1 & 2 & 3 & 4 & 5 & 6 & 7 & 8 \\
\hline Analyst & & No & No & No & Yes & No & Yes & No & No \\
A & & No & No & No & No? & $?$ & - & No & No? \\
F & & No & No & No & Yes & No & No & No & - \\
R & No & $44 *$ & 73 & $78 *$ & 69 & $63 *$ & 72 & $67 *$ & $59 *$ \\
MESS & Yes & 43 & $78 *$ & 5 & $76 *$ & 58 & $79 *$ & 50 & 49 \\
& & & & & & & & &
\end{tabular}

* Strongest weight

Table 2

Case statistics 


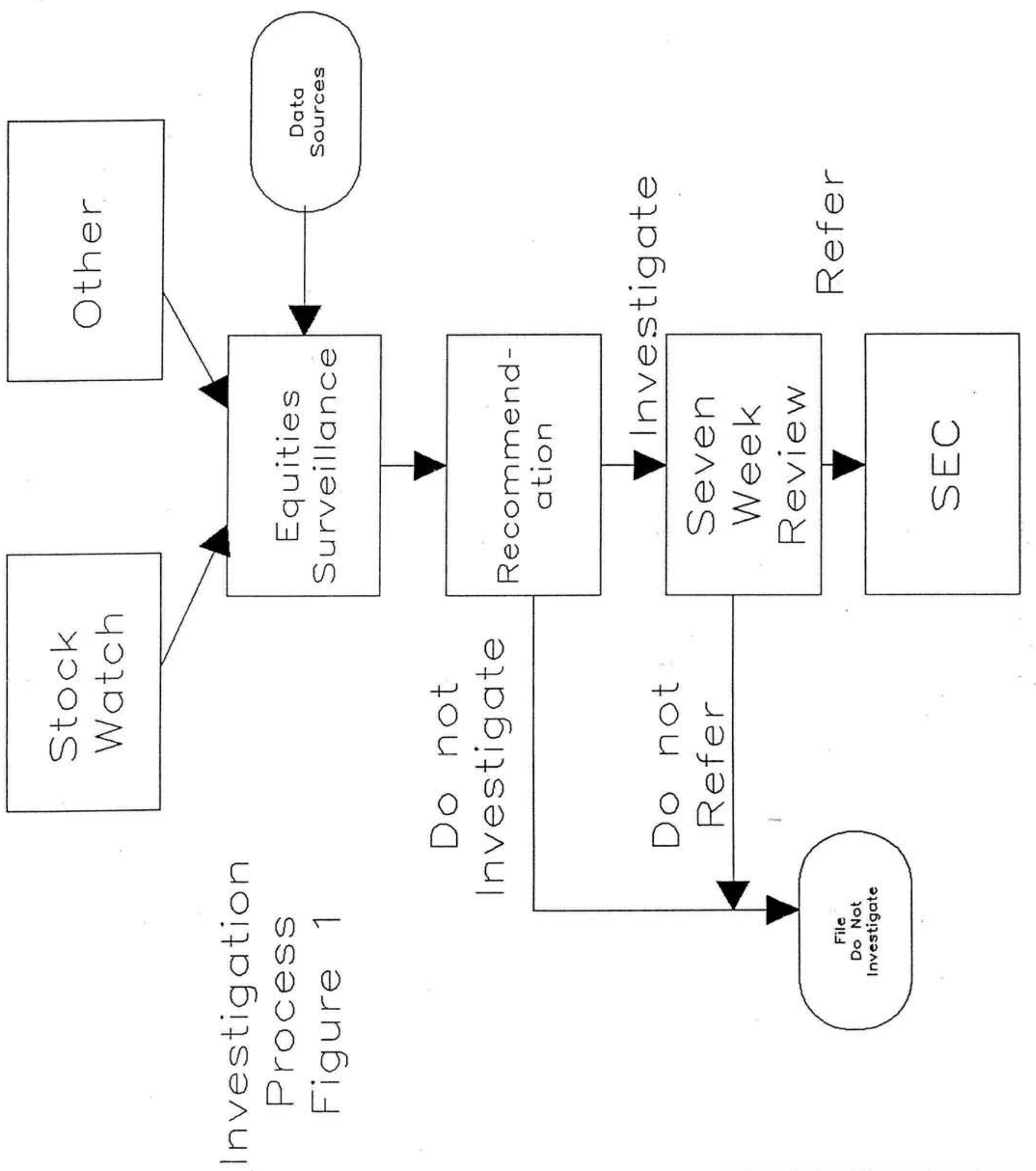




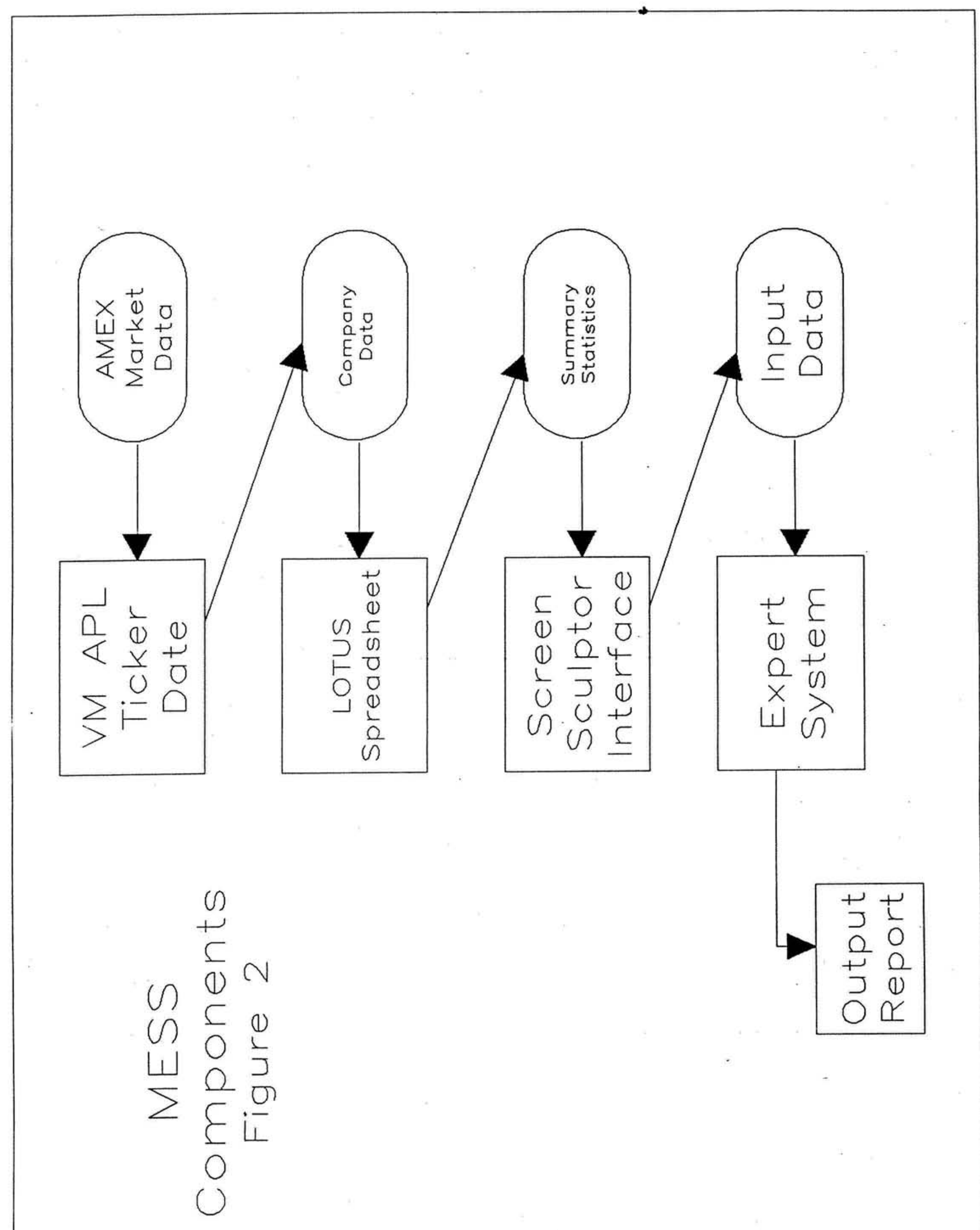


IF :

and

(1) The investigation is for insider trading.

(2) [EXPECTEDMOVEMENT $]<0$

and (3)

$([$ LARGESELL $]+[$ SECONDSELL $]+[$ THIRDSELL $]) /[$ VOLUMEPERIOD $]>=. X$

THEN :

(1) Open an investigation. - Confidence $=$ Y $/ 100$

NOTE: If the investigation is for insider trading and the expectedmovement is $<0$ and the three largest sellers account for $X \%$ or more of the volume, then investigate $\mathrm{p}=\mathrm{Y}$.

RULE NUMBER: 130

IF :

(1) The investigation is for insider trading.

and (2) The news is that there will be a takeover or merger

and (3) For the merger or takeover, the AMEX company is being acquired

and (4) ([TAKEOVERPRICE] $-[$ LOWGAIN $]) /[$ LOWGAIN $]>X$

THEN :

(1) Open an investigation. - Confidence=Y $/ 100$

NOTE: If the investigation is for insider trading and the AMEX firm is being acquired and the takeoverprice-the low before divided by the low before is greater than. $X$, investigate $p=Y$

Two Examples of MESS Rules

Figure 3 